\title{
Estabelecimento in vitro e aclimatização de Lippia alba (Mill.) N. E. Brown
}

\author{
LUZ, J.M.Q'; SANTOS, V.A.'; RODRIGUES, T.M.1; ARRIGONI BLANK, M.F.2; ASMAR, S.A. ${ }^{*}$ \\ 'Universidade Federal de Uberlândia - UFU, Instituto de Ciências Agrárias, Campus Umuarama, Av. Amazonas \\ s/n, CEP 38400-902, Uberlândia - MG, Brasil. *siasmar@yahoo.com.br \\ 2Universidade Federal de Sergipe - UFS, Departamento de Engenharia Agronômica, Av. Marechal Rondon s/n, \\ CEP 49100-000, São Cristóvão, SE.
}

\begin{abstract}
RESUMO: O presente trabalho teve por objetivo estabelecer in vitro a espécie Lippia alba (Mill.) N. E. Brown e promover a aclimatização de mudas dessa espécie. Para isso, foi testada a influência de diferentes concentrações e tempos de imersão em hipoclorito de sódio na assepsia dos explantes. Segmentos nodais foram imersos em hipoclorito de sódio nas concentrações 0,$4 ; 0,6 ; 0,8$ e $1,0 \%$ e nos tempos 8,12 e 16 minutos. Após 30 dias avaliou-se a contaminação bacteriana (\%), número de brotos, número de folhas, e a taxa de sobrevivência (\%). A concentração de $1 \%$ de hipoclorito de sódio foi a mais eficiente no controle da contaminação. Ápices caulinares de $L$. alba foram estabelecidos in vitro em meio MS suplementado com diferentes doses de $\operatorname{BAP}\left(0 ; 0,5 ; 1,0 ; 1,5 \mathrm{mg} \mathrm{L}^{-1}\right)$. Após 140 dias avaliou-se a contaminação (\%), a taxa de sobrevivência (\%), a oxidação (\%) e o número de brotos. Os melhores resultados foram obtidos para a dose $1,5 \mathrm{mg} \mathrm{L}^{-1}$ deste regulador. Para a aclimatização foram testados quatro tipos de substratos: pó de coco + calcário $\left(1 \mathrm{~g} \mathrm{~L}^{-1}\right)$, Plantmax ${ }^{\circledR}+$ calcário $\left(1 \mathrm{~g} \mathrm{~L}^{-1}\right)$, vermiculita + calcário (1 $\left.\mathrm{g} \mathrm{L}^{-1}\right)$ e pó de coco + Plantmax ${ }^{\circledast}$ + vermiculita (1:1:1) + calcário (1 g L-1). Avaliou-se a taxa de sobrevivência $(\%)$, comprimento da parte aérea $(\mathrm{cm})$, comprimento da raiz $(\mathrm{cm})$, massa fresca da parte aérea e da raiz ( $\mathrm{g}$ ), e a massa seca da parte aérea e da raiz (g). Os melhores resultados foram obtidos quando com o substrato comercial Plantmax ${ }^{\circledast}$.
\end{abstract}

Palavras-chave: micropropagação, hipoclorito de sódio, substratos

ABSTRACT: In vitro establishment and acclimatization of Lippia alba (Mill.) N. E. Brown The present study aimed to establish the species Lippia alba (Mill.) N. E. Brown in vitro and promote the acclimatization of the seedlings of this species. Therefore, we tested the effect of different concentrations and immersiog times in sodium hypochloritetfor the disinfection of explants. Nodal segments were immersed in sodium hypochlorite at the different concentrations of ,. $4 ;, .6 ;, .8$ and, $.0 \%$ during the different times of 8,12 and 16 minutes. After 30 days, bacterial contamination (\%), number of shoots, number of leaves and survival rate (\%) were evaluated. The $1 \%$ concentration of sodium hypochlorite was more effective in controlling contamination. Shoot apices of $L$. alba were established in vitro on MS medium supplemented with different concentrations of BAP $\left(;, .5 ;, .0 ;, .5 \mathrm{mg} \mathrm{L}^{-1}\right)$. After 140 days, we evaluated the contamination (\%), survival rate (\%), oxidation (\%) and number of shoots. The best results were obtained when we used the dose of ,.5 mg L-1 of this regulator. For acclimatization, we tested four types of substrates: coconut powder + lime $\left(1 \mathrm{~g} \mathrm{~L}^{-1}\right)$, Plantmax ${ }^{\oplus}+$ lime $\left(1 \mathrm{~g} \mathrm{~L}^{-1}\right)$, vermiculite + lime $(1$ $\left.\mathrm{g} \mathrm{L}^{-1}\right)$ and coconut powder + Plantmax ${ }^{\oplus}+$ vermiculite $(1: 1: 1)+$ lime $\left(1 \mathrm{~g} \mathrm{~L}^{-1}\right)$. We evaluated the survival rate $(\%)$, shoot length $(\mathrm{cm})$, root length $(\mathrm{cm})$, fresh weight of shoot and root $(\mathrm{g})$ and dry weight of shoot and root $(\mathrm{g})$. The best results were obtained when using the substrate Plantmax ${ }^{\circledR}$.

Keywords: micropropagation, sodium hypochlorite, substrates

\section{INTRODUÇÃO}

Lippia alba (Mill.) N. E. Brown (Verbenaceae)

é uma planta medicinal nativa da América do Sul amplamente distribuída em todo o território brasileiro, popularmente conhecida como erva cidreira, erva cidreira brasileira, erva cidreira do campo, alecrim, alecrim do mato, alecrim do campo, dentre outras 
denominações. É uma planta bastante utilizada na medicina popular no tratamento de diversos males, como cólicas, indigestão, dores, náuseas e espasmos, combate insônia e asma, possuindo ainda ação anticonvulsivante e antifúngica (Rao et al., 2000).

A micropropagação é um método alternativo de propagação vegetativa amplamente estudado nas mais diversas espécies vegetais, sendo a técnica dentro da cultura de tecidos que mais tem difundido e encontrado aplicações práticas comprovadas. Entre as vantagens de sua utilização, estão: a possibilidade de obtervárias plantas a partir de um explante inicial, independentemente da estação do ano; a redução do tempo e da área necessária à propagação da espécie; as melhores condições sanitárias; a reprodução do genótipo da planta-mãe, com fidelidade durante a multiplicação e; a propagação vegetativa de espécies difíceis de serem propagadas por outros métodos (Erig \& Schuch, 2005). Dentre as fases da micropropagação, o estabelecimento e a aclimatização são considerados os mais críticos e, por essa razão, exigem certos cuidados.

O presente trabalho teve por objetivo estabelecer in vitro a L. alba (Mill.) N. E. Brown e promover a aclimatização de mudas dessa espécie.

\section{MATERIAL E MÉTODOS}

\section{Tratamento das matrizes e pré-assepsia do material \\ Os experimentos foram conduzidos no} Laboratório de Biotecnologia do Instituto de Ciências Agrárias da Universidade Federal de Uberlândia.

As matrizes doadoras dos explantes foram cultivadas em casa de vegetação e pulverizadas com $2 \mathrm{~g} \mathrm{~L}^{-1}$ de fungicida Cerconil ${ }^{\otimes}$ durante 15 dias. Ramos jovens foram coletados e lavados em água corrente por 30 minutos, retirando-se o excesso de lâminas foliares. Em seguida, foram colocados em um recipiente com 10 gotas de detergente neutro em $1 \mathrm{~L}$ de água destilada durante 10 minutos, em agitação e, posteriormente, lavados três vezes com água destilada e autoclavada para remoção do detergente.

\section{Concentrações e tempos de imersão em} hipoclorito de sódio no estabelecimento in vitro de L. alba

Em câmara de fluxo laminar, segmentos nodais de aproximadamente $1,5 \mathrm{~cm}$ foram individualizados e imersos em hipoclorito de sódio $(\mathrm{NaOCl})$ em diferentes concentrações $(0,4 ; 0,6 ; 0,8$ e $1,0 \%$ ) e tempos de imersão ( 8,12 e 16 minutos). Em seguida, os explantes foram inoculados em tubos de ensaio contendo $20 \mathrm{~mL}$ de meio MS (Murashige \& Skoog, 1962), contendo $7 \mathrm{~g} \mathrm{~L}^{-1}$ de ágar e $\mathrm{pH}$ ajustado para $5,7 \pm 0,1$ antes da autoclavagem $\left(121^{\circ} \mathrm{C}\right.$ e 1,2 atm por 20 minutos). Após a inoculação, os tubos foram vedados com parafilme e mantidos em sala de crescimento com temperatura de $25 \pm 1^{\circ} \mathrm{C}$, fotoperíodo de 16 horas de luz e intensidade luminosa de $36 \mu \mathrm{mol} \mathrm{m}^{-2} \mathrm{~s}^{-1}$, fornecida por lâmpadas brancas fluorescentes.

O experimento foi instalado em delineamento inteiramente casualizado (DIC) em esquema fatorial $4 \times 3$, sendo quatro concentrações de hipoclorito de sódio e três tempos de imersão no mesmo, totalizando 12 tratamentos com quatro repetições. Cada repetição foi composta por cinco tubos de ensaio, contendo um explante. Os dados foram submetidos à análise de variância utilizandose o programa estatístico Sisvar 4.3 (Ferreira, 2000), utilizando-se o teste de regressão a $5 \%$ de significância.

Decorridos 30 dias, avaliou-se a contaminação (\%), o número de brotos, o número de folhas, e a taxa de sobrevivência (\%).

\section{Cultura de ápices caulinares}

Em câmara de fluxo laminar, os ramos foram imersos em álcool $70 \%$ durante 30 segundos. Em seguida, os ápices caulinares foram assepticamente extraídos, sob lupa estereoscópica binocular, com aumento de 300 vezes e com o auxílio de pequenas pinças, bisturis e estiletes. Após sua retirada, os explantes foram inoculados em tubos de ensaio contendo meio MS suplementado com diferentes concentrações do regulador de crescimento 6-benzilaminopurina (BAP) $\left(0 ; 0,5 ; 1,0 ; 1,5 \mathrm{mg} \mathrm{L}^{-1}\right)$. Após à inoculação, os tubos foram vedados com parafilme e mantidos em sala de crescimento, com temperatura de $25 \pm 1^{\circ} \mathrm{C}$, fotoperíodo de 16 horas de luz e intensidade luminosa de $36 \mu \mathrm{mol} \mathrm{m}^{-2} \mathrm{~s}^{-1}$, fornecida por lâmpadas brancas fluorescentes.

O experimento foi instalado em delineamento inteiramente casualizado (DIC), com quatro doses de BAP e cinco repetições, sendo cada repetição constituída de cinco ápices caulinares. Os dados foram submetidos à análise de variância utilizandose o programa estatístico Sisvar 4.3 (Ferreira, 2000), utilizando-se o teste de regressão a $5 \%$ de significância.

Aos 140 dias, foram avaliadas as características de contaminação (\%), oxidação (\%), taxa de sobrevivência (\%) e o número de brotos.

\section{Aclimatização de mudas de $L$. alba}

Para o processo de aclimatização, foram utilizadas mudas cultivadas in vitro e com 40 DAI (dias após inoculação), já enraizadas e com aproximadamente $6 \mathrm{~cm}$ de altura. A aclimatização

Rev. Bras. PI. Med., Campinas, v.16, n.2, supl. I, p.444-449, 2014. 
constou de três etapas sucessivas. Na $1^{\text {a }}$ etapa, os tubos de ensaio foram abertos e as plântulas ficaram expostas ao ambiente de câmara climatizada durante 15 dias. Para a $2^{a}$ etapa, as plântulas foram retiradas dos tubos de ensaio e lavadas para remover os resíduos de meio de cultura aderidos às raízes, sendo, posteriormente feito o transplantio para bandejas de poliestireno expandido, com 72 alvéolos contendo os diferentes substratos. As mudas permaneceram em ambiente de câmara climatizada durante 20 dias. Nesse período, foram regadas com solução de sais do meio $\mathrm{MS}$. $\mathrm{Na}^{\mathrm{a}}$ etapa, foi feita a transferência da bandeja para casa de vegetação, no qual as mudas permaneceram durante 40 dias.

O delineamento foi o inteiramente casualizado (DIC), constando de quatro misturas de substratos, sendo eles: pó de coco + calcário (1 $\left.\mathrm{g} \mathrm{L}^{-1}\right)$, Plantmax ${ }^{\circledR}+$ calcário (1 $\left.\mathrm{g} \mathrm{L}^{-1}\right)$, vermiculita + calcário $\left(1 \mathrm{~g} \mathrm{~L}^{-1}\right)$ e pó de coco + Plantmax ${ }^{\circledR}+$ vermiculita $(1: 1: 1)$ + calcário (1 g L-1). Foram utilizadas cinco repetições, sendo cada repetição constituída de cinco plântulas. Os dados de porcentagem foram transformados em arco seno da raiz quadrada $(x / 100)$ e submetidos à análise de variância, pelo teste $\mathrm{F}$ e, quando significativos, as médias foram comparadas pelo teste de Tukey $(p<0,05)$, utilizando-se o programa estatístico Sisvar (Ferreira, 2000).

Após o término das três etapas ( 75 dias), foram avaliadas as características taxa de sobrevivência (\%), comprimento da parte aérea $(\mathrm{cm})$, comprimento da raiz $(\mathrm{cm})$, número de folhas e massa fresca e seca da parte aérea e da raiz (g).

\section{RESULTADOS E DISCUSSÃO}

\section{Concentrações e tempos de imersão em hipoclorito de sódio no estabelecimento in vitro de $L$. alba.}

A interação entre as concentrações de hipoclorito de sódio e os tempos de imersão não foi significativa. No entanto, observou-se que para todas as variáveis analisadas, a concentração de $1 \%$ de hipoclorito de sódio foi a mais eficiente.

O número de brotos pode ser representado por uma equação linear positiva, sendo o aumento de acordo com o aumento das concentrações de hipoclorito de sódio, com valores de 0,$41 ; 1 ; 0,83$ e 1,91 brotos, para as concentrações de 0,$4 ; 0,6$; 0,8 e $1 \%$ de hipoclorito de sódio, respectivamente (Figura 1A).

Quanto maior a concentração de hipoclorito de sódio utilizada, menor foi a ocorrência de contaminação (Figura 1B). Quando se utilizou a concentração de $0,4 \%$, a contaminação foi de
$66,67 \%$. Para as concentrações de 0,6 e $0,8 \%$, a contaminação foi de $48,33 \%$ e, na concentração $1 \%$, a contaminação foi de $23,33 \%$.

Na desinfestação de segmentos nodais de Eucalyptus dunni com diferentes concentrações de hipoclorito de sódio, Almeida et al. (2008) também obtiveram menor índice de contaminação bacteriana utilizando $1 \%$ de hipoclorito de sódio.

Para a característica número de folhas, foram observadas diferenças significativas entre as concentrações testadas, seguindo o mesmo comportamento do número de brotos, com valores de 1,$66 ; 6 ; 4,58$ e 10,83 folhas, para as concentrações de 0,$4 ; 0,6 ; 0,8$ e $1 \%$ de hipoclorito de sódio, respectivamente (Figura $1 \mathrm{C}$ ).

A sobrevivência dos explantes foi de $33,33 \%$ quando se utilizou $0,4 \%$ de hipoclorito de sódio. Estes valores foram maiores a medida que se aumentou a concentração de $\mathrm{NaOCl}$, podendo essa variável ser representada por uma equação linear. O valor máximo de sobrevivência $(76,66 \%)$ foi obtido quando utilizado $1 \%$ de $\mathrm{NaOCl}$ (Figura 1D).

Em relação aos tempos de imersão, o tempo de 16 minutos proporcionou maior porcentagem de sobrevivência $(56,25 \%)$ (Tabela 1), demonstrando que este pode ser utilizado na desinfestação de explantes de L. alba. Costa et al. (2007) utilizaram hipoclorito de sódio a $0,8 \%$ durante 16 minutos para desinfestação de Lippia sidoides, tempo que corrobora com o encontrado neste trabalho.

Não houve diferença significativa quando se utilizou diferentes tempos de imersão para as características contaminação e número de brotos (Tabela 1).

Conclui-se assim, que a concentração de $1 \%$ de hipoclorito de sódio e o tempo de imersão por 16 minutos promovem desinfestação satisfatória e maior taxa de sobrevivência no estabelecimento in vitro de explantes de $L$. alba.

\section{Cultura de ápices caulinares}

Verificou-se que o regulador de crescimento BAP foi eficiente na regeneração dos ápices caulinares. Para a característica contaminação, não houve diferença significativa entre os tratamentos.

Para o número de brotos, os resultados foram eficazes quando se utilizou $1,5 \mathrm{mg} \mathrm{L}^{-1}$ desta citocinina (Figura 2), observando-se que quanto maior sua dosagem, maior o número de brotações.

A taxa de sobrevivência seguiu a mesma tendência do número de brotos, sendo esta maior, quando se utilizou $1,5 \mathrm{mg} \mathrm{L}^{-1}$ de BAP (Figura 3). Asmar et al. (2012), testando diferentes concentrações de BAP sobre a proliferação in vitro de brotos de $L$. alba, obtiveram maiores brotações quando utilizaram $1,5 \mathrm{mg} \mathrm{L}^{-1}$ deste regulador. A eficiência desta citocinina na multibrotação 


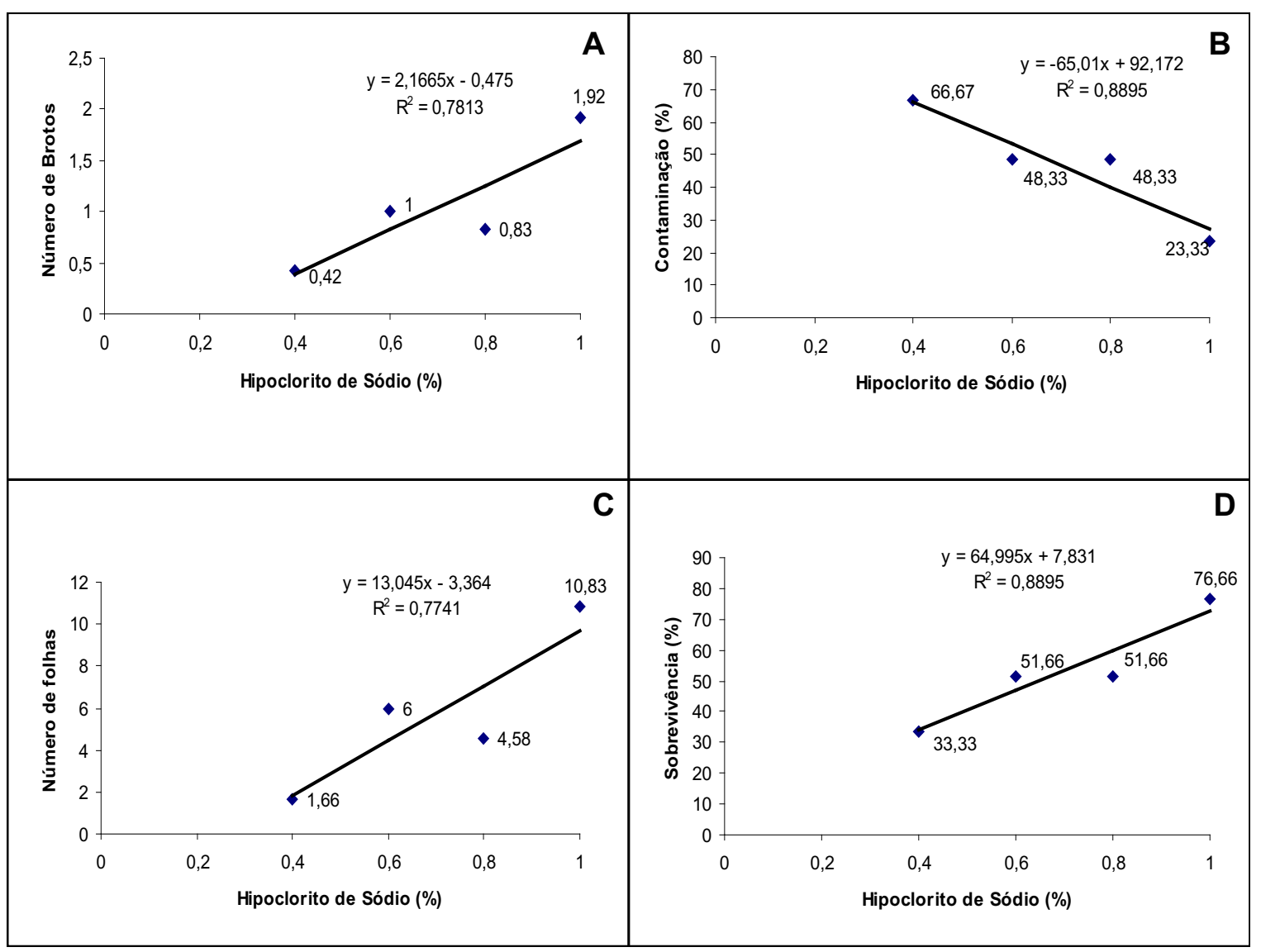

FIGURA 1. A - número de brotos, B - contaminação (\%), C - número de folhas, D - taxa de sobrevivência (\%) de segmentos nodais de $L$. alba, em função de diferentes concentrações de hipoclorito de sódio.

TABELA 1. Contaminação (\%), número de brotos, número de folhas e taxa de sobrevivência (\%) de segmentos nodais de $L$. alba, em função de diferentes tempos de imersão em hipoclorito de sódio.

\begin{tabular}{ccccc}
\hline $\begin{array}{c}\text { Tempos de Imersão } \\
\text { (minutos) }\end{array}$ & $\begin{array}{c}\text { Taxa de Sobrevivência } \\
(\mathbf{\%})\end{array}$ & $\begin{array}{c}\text { Contaminação } \\
\mathbf{( \% )}\end{array}$ & Número de Brotos & $\begin{array}{c}\text { Número de } \\
\text { Folhas }\end{array}$ \\
\hline 8 & $43,75 \mathrm{ab}$ & $1,25 \mathrm{a}$ & $7,62 \mathrm{a}$ & $56 \mathrm{ab}$ \\
12 & $40,00 \mathrm{~b}$ & $1,18 \mathrm{a}$ & $6,56 \mathrm{a}$ & $60 \mathrm{a}$ \\
16 & $56,25 \mathrm{a}$ & $0,68 \mathrm{a}$ & $3,12 \mathrm{a}$ & $43 \mathrm{~b}$ \\
\hline $\mathrm{CV}(\%)$ & 39,88 & 79,02 & 97,15 & 34,09 \\
\hline
\end{tabular}

Médias seguidas das mesmas letras nas colunas, não diferem estatisticamente entre si pelo teste de Tukey $(p<0,05)$.

de plantas da família Verbenaceae também foi reportada por Balaraju et al. (2008).

Um protocolo de regeneração de meristemas apicais de Melia azedarach L. foi desenvolvido utilizando-se meio MS suplementado com $0,5 \mathrm{mg}$ $\mathrm{L}^{-1}$ de BAP o qual promoveu maior proliferação de gemas (Vila et al., 2002). Trabalhando com diferentes associações de citocininas no cultivo in vitro de hortelã-pimenta (Mentha x Piperita L.), Asmar et al. (2011) concluíram que o BAP também foi eficiente na multiplicação desta espécie.

Quanto à oxidação, esta foi inversamente proporcional à taxa de sobrevivência. No tratamento com 1,5 mg L-1 de BAP ocorreu 7,65\% de oxidação, sendo essa a menor dentre as demais dosagens utilizadas; a maior oxidação ocorreu no tratamento sem adição de $\operatorname{BAP}(15,94 \%)$ (Figura 3$)$.

Desta forma, pode-se concluir que para o estabelecimento in vitro de ápices caulinares de $L$. alba. é necessário utilizar o meio MS suplementado com 1,5 mg L ${ }^{-1}$ de BAP.

\section{Aclimatização de mudas de $L$. alba}

Para a característica comprimento de raiz, não houve diferença significativa entre os substratos utilizados. A maior taxa de sobrevivência foi obtida quando se utilizou o substrato comercial Plantmax ${ }^{\circledR}$ + calcário (80\%), e a menor foi obtida 


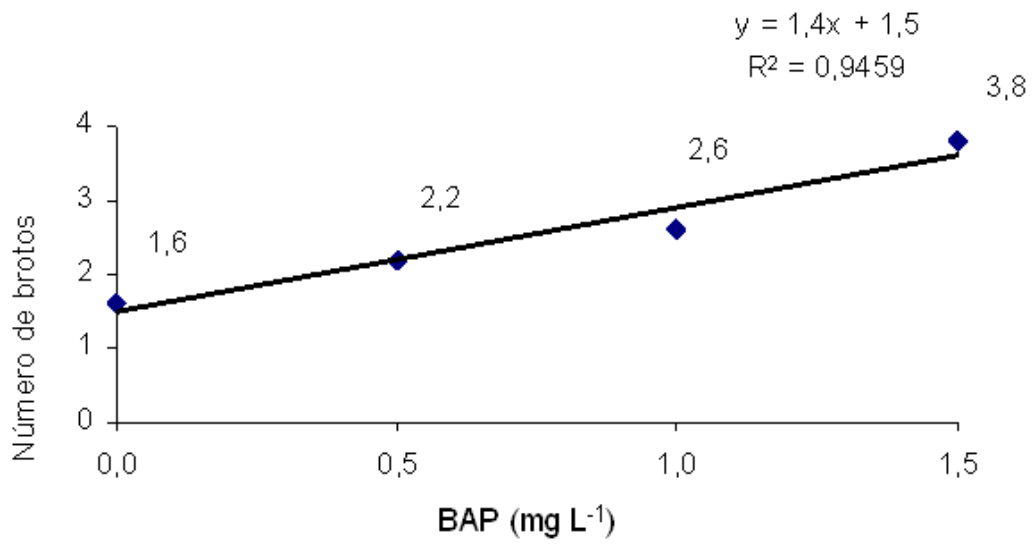

FIGURA 2. Número de brotos em ápices caulinares de L. alba inoculados em meio MS suplementado com diferentes doses de BAP.

quando se utilizou o substrato pó de coco + calcário (40\%) (Tabela 2). Almeida (2009) trabalhando com gerânio (Pelargonium graveolens L.) obteve maiores porcentagens de sobrevivência utilizando os substratos pó de coco + Biosafra + calcário e pó de coco + Biosafra ${ }^{\circledR}$ calcário + vermiculita (1:1). Silva et al. (2007) relataram maior taxa de sobrevivência de Aloe vera $\mathrm{L}$. ao final do período de aclimatização (60 dias), nos substratos areia, Plantmax $®$ e casca de arroz carbonizada + Plantmax ${ }^{\circledR}$ (1:1), os quais apresentaram respectivamente, 80,95 e $75 \%$ de sobrevivência.

Com relação ao comprimento da parte aérea, os maiores valores foram obtidos quando se utilizaram: o substrato comercial Plantmax ${ }^{\circledR}+$ calcário; a mistura de todos os substratos (pó de coco + vermiculita + Plantmax + calcário ); e a vermiculita + calcário (Tabela 2).

Para o número de folhas, o menor valor foi obtido quando se utilizou o pó de coco + calcário como substrato, diferindo dos demais tratamentos (Tabela 2).

Quanto à massa fresca da parte aérea, os resultados mais satisfatórios foram obtidos quando se utilizou o substrato comercial Plantmax ${ }^{\circledR}$ + calcário, vermiculita + calcário e a mistura de todos os substratos + calcário (Tabela 3). Segundo Hoffmann et al. (2001), o Plantmax apresenta boas características (porosidade, textura, drenagem, baixa compactação, presença de nutrientes e pH adequados ao desenvolvimento) favorecendo o crescimento das mudas após emissão das raízes adventícias. Por essas razões, é o substrato recomendado para a fase de aclimatização de plantas micropropagadas.

Para a massa fresca da raiz, massa seca da parte aérea e massa seca da raiz, não houve diferença significativa entre os diferentes substratos (Tabela 3).

Conclui-se que para realizar a aclimatização das mudas de L. alba, o uso do substrato comercial Plantmax ${ }^{\circledR}$ permitiu com que as plantas desenvolvessem características desejáveis para esta fase, tais como: a taxa de sobrevivência, o comprimento da parte aérea, o número de folhas, e a massa fresca da parte aérea.
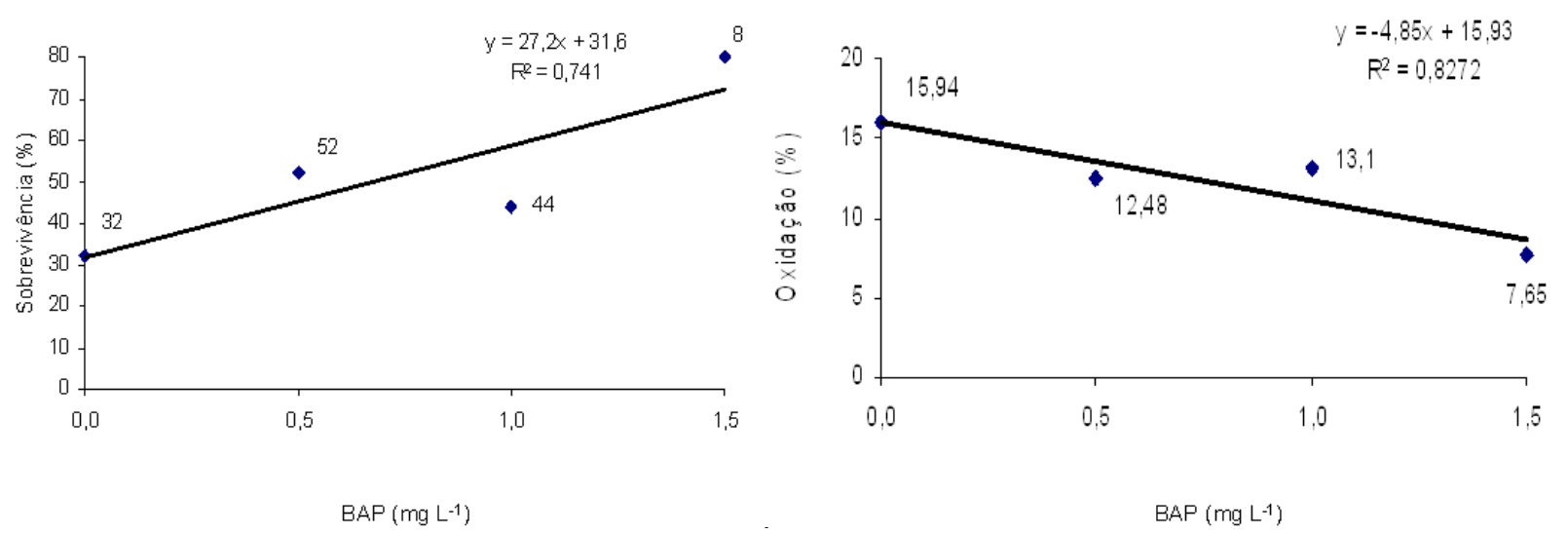

FIGURA 3. Sobrevivência (\%) e oxidação (\%) de ápices caulinares de $L$. alba inoculados em meio MS suplementado com diferentes doses de BAP.

Rev. Bras. PI. Med., Campinas, v.16, n.2, supl. I, p.444-449, 2014. 
TABELA 2. Sobrevivência, comprimento da parte aérea, comprimento da raiz e número de folhas de mudas de L. alba aclimatizadas em diferentes substratos.

\begin{tabular}{ccccc}
\hline Substrato & Taxa de Sobrevivência (\%) & Comprimento parte aérea $(\mathrm{cm})$ & Comprimento raiz $(\mathrm{cm})$ & Número de folhas \\
\hline Pó de coco & $40 \mathrm{~b}$ & $5,32 \mathrm{~b}$ & $2,68 \mathrm{a}$ & $1,8 \mathrm{~b}$ \\
Plantmax® & $80 \mathrm{a}$ & $15,43 \mathrm{a}$ & $5,40 \mathrm{a}$ & $7,56 \mathrm{a}$ \\
Vermiculita & $60 \mathrm{ab}$ & $11,48 \mathrm{ab}$ & $3,87 \mathrm{a}$ & $6,68 \mathrm{a}$ \\
Mistura & $64 \mathrm{ab}$ & $12,32 \mathrm{a}$ & $4,00 \mathrm{a}$ & $6,32 \mathrm{a}$ \\
\hline CV $(\%)$ & 26,94 & 32,71 & 40,68 & 32,75 \\
\hline
\end{tabular}

Médias seguidas das mesmas letras nas colunas, não diferem estatisticamente entre si, pelo teste de Tukey $(p<0,05)$.

TABELA 3. Massa fresca da parte aérea e da raiz, massa seca da parte aérea e da raiz de mudas de $L$. alba aclimatizadas com diferentes substratos.

\begin{tabular}{lllll}
\hline Substrato & \multicolumn{1}{l}{ Massa fresca parte aérea $(\mathrm{g})$} & Massa fresca raiz $(\mathrm{g})$ & Massa seca parte aérea $(\mathrm{g})$ & Massa seca raiz $(\mathrm{g})$ \\
\hline Pó de coco & $0,72 \mathrm{~b}$ & $0,30 \mathrm{a}$ & $0,41 \mathrm{a}$ & $0,24 \mathrm{a}$ \\
Plantmax® & $3,54 \mathrm{a}$ & $0,65 \mathrm{a}$ & $0,94 \mathrm{a}$ & $0,47 \mathrm{a}$ \\
Vermiculita & $2,75 \mathrm{a}$ & $0,69 \mathrm{a}$ & $0,71 \mathrm{a}$ & $0,36 \mathrm{a}$ \\
Mistura & $3,46 \mathrm{a}$ & $0,38 \mathrm{a}$ & $0,67 \mathrm{a}$ & $0,20 \mathrm{a}$ \\
\hline CV $(\%)$ & 40,50 & 45,41 & 53,32 & 47,81 \\
\hline
\end{tabular}

Médias seguidas das mesmas letras nas colunas, não diferem estatisticamente entre si pelo teste de Tukey $(p<0,05)$.

\section{AGRADECIMENTOS}

Os autores agradecem a Coordenação de Aperfeiçoamento de Pessoal de Nível Superior (CAPES) e ao Conselho Nacional de Desenvolvimento Científico e Tecnológico (CNPq) pelo auxílio financeiro recebido.

\section{REFERÊNCIA}

ALMEIDA, J.R.; MARTINS, C.R.; DUTRA, L.F. Desinfestação de segmentos nodais de Eucalyptus dunnii visando estabelecimento in vitro. Revista da FZVA, v.15, n.1, p. 54-60, 2008.

ALMEIDA, S. A. de. Micropropagação, teor e constituição química do óleo essencial de Gerânio (Pelargonium graveolens L.). 2009. 66 p. Dissertação Mestrado. Universidade Federal de Sergipe, São Cristóvão.

ASMAR, S.A.; RESENDE, R.F.; ARARUNA, E.C.; MORAIS, T.P.; LUZ, J.M.Q. Citocininas na multiplicação in vitro de hortelã-pimenta (Mhenta x Piperita L.). Revista Brasileira de Plantas Medicinais, v. 13, especial, p.533-538, 2011.

ASMAR, S.A.; RESENDE, R.F.; ARARUNA, E.C.; MORAIS, T.P.; LUZ, J.M.Q. Concentrações de BAP sobre a proliferação in vitro de brotos de Lippia alba [(Mill.) N. E. Brown]. Revista Brasileira de Plantas Medicinais, v. 14, especial, p.149-153, 2012.

BALARAJU, K. et al. Micropropagation of Vitex agnuscastus (Verbenaceae) - a valuable medicinal plant. In vitro Cellular and Developmental Biology - Plant,
Wallingford, v.44, n.5, p.436-441, 2008.

COSTA, S.; ARRIGONI-BLANK M. F.; BLANK A. F.; MENDONÇA A. B.; AMANCIO V. F.; LEDO A. S. Estabelecimento de alecrim-pimenta in vitro. Horticultura Brasileira, Brasília, v.25, n.1, p. 68-72, 2007.

ERIG, A.C.; SCHUCH, M.W. Micropropagação fotoautotrófica e uso da luz natural. Ciência Rural, v.35, n.4, p.961-5, 2005.

FERREIRA, D.F. 2000. Sisvar 4.3: sistema de análises de variância para dados balanceados: programa de análises estatísticas e planejamento de experimentos. Lavras: UFLA/DEX, 2000.

HOFFMANN, A.; PASQUAL, M.; CHALFUN, N.N.J.; FRÁGUAS, C.B. Efeito de substratos na aclimatização de plantas micropropagadas de porta-enxertos de macieira 'Marubakaido'. Ciência e Agrotecnologia, Lavras, v.25, n.2, p.462-467, 2001.

MURASHIGE, T.; SKOOG, F. A revised medium for rapid growth and bioassays with tobacco tissue cultures. Physiologia Plantrarum, v.15, n.3, p.473-97, 1962.

RAO, G.P.; SINGH, M.; SINGH, P.; CATALAN, C.; KAPOOR, I.P.S.; SINGH, O.P.; SINGH, G. Studies on chemical constituents and antifungal activity of leaf oil of Lippia alba (Mill.). Indian Journal of Chemical Technology, v.7, n.6, p.332-35, 2000.

SILVA, C.G.; DEBIASI, C.; PESCADOR, R. Enraizamento in vitro e aclimatização de mudas micropropagadas de Aloe vera L. Revista Brasileira de Plantas Medicinais, Botucatu, v.9, n.1, p.29-35, 2007.

VILA, S; SCOCCHI, A; MROGINSKI, L. Plant regeneration from shoot apical meristems of Melia azedarach $L$. (Meliaceae). Acta Physiologiae Plantarum, v.24, n.2, p.195-199, 2002. 